\title{
Perceptions of organizational capacity to promote physical activity in Canada and ParticipACTION's influence five years after its relaunch: a qualitative study
}

\author{
Subha Ramanathan, PhD (1); Guy Faulkner, PhD (1); Tanya Berry, PhD (2); Sameer Deshpande, PhD (3); \\ Amy E. Latimer-Cheung, PhD (4); Ryan E. Rhodes, PhD (5); John C. Spence, PhD (2); Mark S. Tremblay, PhD (6)
}

This original qualitative research article has been peer reviewed.

Tweet this article

\begin{abstract}
Introduction: ParticipACTION is a Canadian physical activity communications and social marketing organization relaunched in 2007. The purpose of this study was to qualitatively investigate organizational capacity for physical activity promotion among Canadian organizations, and the influence of ParticipACTION on capacity five years after relaunch.
\end{abstract}

Methods: Using a purposive sampling strategy, semi-structured telephone interviews were conducted with 44 key informants representing national, provincial, and local organizations with a mandate to promote physical activity. Interview data were analyzed using a thematic analytic approach.

Results: Organizational capacity in terms of partnerships and collaborations, and the general climate for physical activity promotion have improved since ParticipACTION's relaunch. Although financial resources reduced the ability of organizations to fulfil their mandates, internal factors such as skilled employees and sponsorships, and external factors such as technological improvements in communication and information sharing helped to offset this strain. There were mixed feelings on ParticipACTION's contribution to capacity. While ParticipACTION has brought more attention to inactivity, this was perceived as a complement to work already taking place. While some organizations perceived ParticipACTION's relaunch as competition to funding and access to popular media, others found it as an opportunity to co-brand social marketing campaigns, utilizing ParticipACTION's products and reputation.

Conclusion: According to participants, organizational capacity to promote physical activity in Canada has increased since 2007 in subtle but important ways because of a strong climate for physical activity promotion, skilled employees, and information sharing technology. Organizational capacity changes were minimally attributed to ParticipACTION.

Keywords: physical activity, health promotion, organizational capacity

\section{Introduction}

To reverse the 20-year old trend of declining physical activity and physical fitness levels in Canada, ${ }^{1-4}$ coordinated and multilevel action is required. ParticipACTION is a physical activity communications and social marketing organization launched in the fall of 1971 to promote physical activity in Canada. ${ }^{5}$ Due to funding cuts, ParticipACTION ceased operations in 2001. Although a comprehensive national

\section{Highlights}

- There were mixed perceptions of ParticipACTION's contribution to capacity to promote physical activity in Canada.

- Partnerships and collaborations have strengthened physical activity promotional efforts over five years since 2007.

- Although information sharing technology and skilled employees have helped to maximize resources, financial infrastructure remains a key barrier to physical activity promotion.

physical activity plan has yet to be released, the federal government made a financial contribution to physical activity promotion by re-establishing ParticipACTION in 2007. ParticipACTION's relaunch was informed by a federally commissioned feasibility study that showed no alternate organization had provided coordinated or sustained national physical activity campaigns between 2001 to 2007. The focus of the new ParticipACTION was social marketing, communications, and partnership synergy. ${ }^{6}$ Baseline information was collected before the launch of the new ParticipACTION to form the basis of ongoing monitoring and evaluation. Framed as a public health natural experiment, ${ }^{7}$ evidence was collected from a populationbased survey ${ }^{8}$, key informant surveys, and interviews ${ }^{9,10}$ in order to examine capacity, readiness, and advocacy for physical

\section{Author references:}

1. School of Kinesiology, University of British Columbia, Vancouver, British Columbia, Canada

2. Faculty of Kinesiology, Sport, and Recreation, University of Alberta, Edmonton, Alberta, Canada

3. Faculty of Management, University of Lethbridge, Lethbridge, Alberta, Canada

4. School of Kinesiology and Health Studies, Queen's University, Kingston, Ontario, Canada

5. School of Exercise Science, Physical and Health Education, University of Victoria, Victoria, British Columbia, Canada

6. Healthy Active Living and Obesity Research Group, Children's Hospital of Eastern Ontario Research Institute, Ottawa, Ontario, Canada

Correspondence: Guy Faulkner, School of Kinesiology, University of British Columbia, 2146 Health Sciences Mall, Room 4606, Vancouver, BC V6T 1Z3; Tel: 604-822-2990;

Fax: 604-822-6842; Email: guy.faulkner@ubc.ca 
activity promotion among physical activity organizations. This study focusses on interview data examining capacity for physical activity promotion among organizations and perceptions of the new ParticipACTION five years after its relaunch.

At baseline, a theoretical model with three indicators was used as a framework for understanding perceptions of organizational capacity to promote physical activity. ${ }^{11}$ This framework was initially developed and validated in the Canadian context and showed that organizational capacity for health promotion could be enhanced with increases in individual dimensions or interactions between dimensions. Additional information about this model is published elsewhere. ${ }^{9}$ The first indicator was leadership and referred to the development of community partnerships, collaborations, and linkages. The second indicator was will/policy making and referred to the process of developing an organizational vision or mission (will to act), and political will among target groups to implement and sustain initiatives. The final indicator, infrastructure, referred to both human and financial resources for health promotion, and the development of skills and a supportive system within the health sector. ${ }^{11,12}$ Baseline research was designed to establish a foundation for subsequent evaluations of physical activity promotion capacity at the organizational level. Overall, the three-indicator model was helpful in understanding the strengths and challenges faced by Canadian organizations promoting physical activity. Findings also suggested that the role of partnerships on leadership capacity and contributions from large health organizations (without a mandate to promote physical activity) warranted further attention.

The current study was undertaken five years after the launch of the new ParticipACTION. The objectives of this study were two-fold: 1) to compare perceptions of capacity at baseline and follow-up, and 2) explore whether ParticipACTION was perceived as enhancing organizational capacity to promote physical activity in Canada. Through this work, we endeavoured to fill knowledge gaps on whether and how social marketing organizations like ParticipACTION can influence organizational capacity and ultimately population physical activity levels, and provide recommendations for future practice.

\section{Methods}

\section{Sampling}

Using a similar sampling approach as the baseline study $^{9}$, semi-structured interviews were conducted with key informants (e.g. physical education teachers, program coordinators at recreation centres, and managers in governmental organizations). Informants were primarily recruited from respondents of a web survey on ParticipACTION's influence on organizational capacity. ${ }^{13}$ Baseline contacts, members of the ParticipACTION Partner Networks (English and French), and provincial lead organizations on an active school travel intervention were sent email invitations with a survey link ( $n=3707$ ). At the end of the survey, participants $(n=540)$ were asked whether they were interested in taking part in a telephone interview. About one-third ( $n=177$ ) expressed interest and 62 were selected and sent email invitations. Similar to the sampling strategy at baseline ${ }^{9}$, participants were purposefully selected from a range of organizational sectors, mandates, provinces and territories to yield a heterogeneous sample. In the end, 38 agreed to an interview (cooperation rate $=61.3 \%$ ), of which nine also took part in the baseline study. ${ }^{9}$

To ensure representation from all provinces and territories, and broader representation with respect to mandates and organizational characteristics (e.g. large health organizations without a specific mandate to promote physical activity), an additional 10 individuals who had not taken part in the survey were invited to participate. These individuals were selected from a list of delegates who had attended a Pan-Canadian meeting (Fredericton, New Brunswick in May 2013) to discuss a national physical activity strategy. Six consented to participate, yielding a total of 44 participants. This sample size was comparable to the baseline study ${ }^{9}$ and to other studies examining capacity for health promotion. ${ }^{14}$ In the end, every province and territory was represented (see Table 1). The organizational level breakdown was 12 national (coded N1-N12), 18 provincial or territorial (coded PT1-PT18), and 14 local organizations (coded L1-L14). The sample also included 10 governmental, 24 not-for-profit
TABLE 1

Informants from provincial, territorial or local organizations by province or territory

\begin{tabular}{lc}
\multicolumn{1}{c}{ Province/Territory } & Informants (n) \\
\hline British Columbia & 6 \\
Alberta & 3 \\
Saskatchewan & 1 \\
Manitoba & 1 \\
Ontario & 8 \\
Quebec & 3 \\
New Brunswick & 1 \\
Nova Scotia & 4 \\
Prince Edward Island & 1 \\
Newfoundland/Labrador & 1 \\
Yukon & 1 \\
Northwest Territories & 1 \\
Nunavut & 1 \\
\hline Total & 32 \\
\hline
\end{tabular}

Note: 12 informants representing national organizations are not represented in this table.

and 7 educational organizations, as well as 3 individuals from the private sector.

\section{Data collection}

Semi-structured telephone interviews (16 to 51 minutes) were conducted between April and July 2013. The baseline interview guide informed by the three-indicator framework was extended to ask about the role of partnerships, engagement with ParticipACTION, and influence on capacity. The interview guide is shown in Table 2. This study was approved by the Health Sciences Research Ethics Board at the University of Toronto (\#28290).

Interviews were conducted in either English (42) or French (2), digitally recorded, and transcribed. As a form of member-checking, participants were emailed their transcript and given an opportunity to add comments or feedback as desired. This process helped to build trust between the researcher and participants, and open dialogue about the interview topics. As well, sharing the transcripts with participants ensured that specific terms (e.g. acronyms) were accurately captured and that punctuation reflected the true meaning of the data. ${ }^{15}$

\section{Data analysis}

Thematic analysis was used to provide a detailed account of organizational capacity. ${ }^{16,17}$ 
TABLE 2

Semi-structured interview guide

\begin{tabular}{|c|c|c|}
\hline Section & Questions & Probes \\
\hline \multirow[t]{7}{*}{ Current capacity } & $\begin{array}{l}\text { What is the mandate of your organization } \\
\text { in terms of promoting physical activity? }\end{array}$ & - Existing programs, activities, policies \\
\hline & & - Policy (will/policymaking) \\
\hline & $\begin{array}{l}\text { How would you define organizational } \\
\text { capacity to promote physical activity? }\end{array}$ & $\begin{array}{l}\text { - Resources: knowledge, skills, human } \\
\text { resources and infrastructure } \\
\text { (infrastructure) }\end{array}$ \\
\hline & & - Partnerships (leadership) \\
\hline & $\begin{array}{l}\text { Given this definition, how would you } \\
\text { describe your organization's current } \\
\text { capacity to promote physical activity? }\end{array}$ & \\
\hline & Has capacity changed over the last 5 years? & \\
\hline & $\begin{array}{l}\text { What are the barriers and facilitators } \\
\text { influencing your organization's capacity } \\
\text { to mobilize and advocate for physical } \\
\text { activity? }\end{array}$ & \\
\hline \multirow[t]{6}{*}{$\begin{array}{l}\text { ParticipACTION's } \\
\text { influence }\end{array}$} & $\begin{array}{l}\text { Has ParticipACTION influenced your } \\
\text { organization's capacity to promote } \\
\text { physical activity? }\end{array}$ & $\begin{array}{l}\text { - Leadership to develop partnerships } \\
\text { - Motivation }\end{array}$ \\
\hline & $\begin{array}{l}\text { What expectations did you have for } \\
\text { ParticipACTION in relation to your } \\
\text { organization? }\end{array}$ & \\
\hline & $\begin{array}{l}\text { Has ParticipACTION provided any } \\
\text { opportunities for your organization? }\end{array}$ & \\
\hline & $\begin{array}{l}\text { Have you faced any challenges in working } \\
\text { with ParticipACTION? }\end{array}$ & \\
\hline & $\begin{array}{l}\text { What role would you like to see } \\
\text { ParticipACTION playing in the future? }\end{array}$ & \\
\hline & $\begin{array}{l}\text { Do you have any recommendations for } \\
\text { ParticipACTION? }\end{array}$ & \\
\hline
\end{tabular}

The first two authors have conducted several qualitative studies using a thematic analysis strategy, including the baseline study led by the second author. Interview transcripts were examined by the first author while simultaneously listening to the digital recording to identify and code major themes. Thematic analysis followed a realist method to report the experiences of participants in relation to the threeindicator theoretical framework and objectives examining organizational capacity. ${ }^{17}$ Quotes served as the unit of analysis. NVivo qualitative software version 10 (QSR International Pty Ltd. 2012) helped to identify patterns in codes, interpret data, understand perspectives among participants, and finally to identify key themes. Themes referring to organizational capacity and their prevalence was taken into consideration. ${ }^{17}$ The flexible use of inductive and deductive analysis allowed for other capacity related themes to emerge if salient. The codebook was shared with the second author and modified at multiple time points to ensure meaningful codes that captured the associated text. The first two authors also checked for code consistency and ensured that new codes were created whenever different perspectives were shared. Similar codes were collapsed when appropriate.

\section{Results}

This section presents key themes, with links to infrastructure, leadership and will/ policymaking dimensions of capacity. Results pertaining to general organizational capacity are presented first (i.e. mandate, capacity to promote physical activity, changes over the last five years, facilitators, and barriers), followed by findings specific to ParticipACTION's influence on organizations (i.e. influence on capacity, expectations and challenges of working with ParticipACTION, future role, and recommendations for ParticipACTION).
Physical activity mandate and congruence with ParticipACTION

Thirty-five out of 44 informants represented organizations committed to increasing physical activity levels through programming, and/or physical activity promotion, and thus aligned with ParticipACTION's mandate to promote physical activity, sport and play. The remaining organizations felt that they had little in common with ParticipACTION's mandate either because of ParticipACTION's focus on children and youth, their organization's focus on research, or their specific approach to promoting physical activity. For example, one informant from a local organization explained,

I think of what we do as [municipal] planners as setting the stage and making sure the props are there. Other people direct the play. ParticipACTION, in my mind, would be one of those that help to direct the play, in other words, encouraging people to get out and walk, use the facilities and neighbourhood that we as planners try to make attractive for walking. (L4)

\section{Organizational capacity to promote physical activity}

In line with our theoretical model of capacity building for health promotion, ${ }^{11}$ elements of organizational capacity to promote physical activity were grouped into three main areas: infrastructure (human and financial resources), leadership (partnerships and collaborations), and will/policymaking (vision, mission).

Local and provincial/territorial organizations emphasized the importance of all three capacity elements in physical activity promotion, though local organizations focussed on unstable elements of capacity like the need for infrastructure (e.g. funding, staff, programming, facilities). One local informant explained, "You have to find space and develop leaders, which allows opportunities for kids to play, and they work in a virtually symbiotic relationship. Without sufficient leaders and without space, there's nowhere for kids to play" (L12). Not surprisingly, organizations primarily consisting of volunteers cited financial resources as a limiting factor, regardless of whether the scope of their work was local, provincial/territorial or national. At the same time, organizations 
were often able to creatively maximize capacity by tapping into leadership aspects, namely building upon existing partnerships or forging new partnerships. One local informant highlighted that collaborative work was important when resources were limited, saying,

I think that we often duplicate things across organizations, where if we worked together and looked at what we had in common,... we could save a lot of money and do a lot better with the money that we have. (L8)

Many local and provincial/territorial informants spoke about working in partnership with other organizations to achieve their goals, while several national informants explained that their role was to build alliances i.e. forge partnerships and share information to strengthen the sector, “... in taking the conversation beyond physical activity specialists to planners-municipal planners, to recreation specialists, to education, to the health sector" (N2).

Informants used a variety of terms that broadly referred to will as a capacity indicator, including political will, strategic plans, long-term plans, visions, champions, goals, and frameworks for action. "Will" was often cited as an area under development and in need of supportive policies. One national informant explained,

I feel that we don't have as big a voice as some of the other industrysectors.... It's a real challenge to find the political will [among] people to embrace sports events like they would [embrace] a movie set or a condominium development. Where they are willing to close roads and take the heat for things like that, the will to close a road for a sporting event isn't as strong. (N7)

There was also a general feeling that it was important to have physical activity promotion explicitly stated in an organizational vision/mission and then to have supportive high-ranking individuals or a board of directors in place for moving agendas forward.

Informants at all levels noted that to successfully promote physical activity and stimulate change, communities and society-at-large ought to feel a need.
"Governments can't do it alone.... We really require that society-at-large embrace [physical activity] in the same way that they've embraced anti-smoking, for example, and drinking and driving, as health issues that require a change in public attitude and view" (PT4). Informants acknowledged that attitude change is a slow process, in part because of an evidence gap that necessitates on-going research in best practices and knowledge exchange: "Evidence-based policies and programsthat's probably the biggest challenge: to know what it is that really does work to engage people to be more physically active. I think what we all struggle with is that" (PT14).

\section{Capacity changes five years after relaunch}

Informants described capacity changes that had taken place since the revival of ParticipACTION. Of the three components of capacity, the greatest changes were seen in leadership, with stronger partners, new partnerships or members. For some, collaborations became established, and organizations had greater credibility within their respective communities or regions, allowing them to build inter-sectoral partnerships and use innovative approaches to physical activity promotion. For instance, one stand-alone national sports organization developed reciprocal membership arrangements with provincial branches to pool financial resources, thereby benefitting from enhanced communication to members, greater exposure, and more opportunities for sponsorships. In other cases, turnover of leaders at the highest levels (within governmental and non-governmental organizations) led to staff being shifted into different roles, facilitating the sharing of new ideas, visions, and programming.

Informants also spoke of restructuring, and funding becoming available for dedicated physical activity and wellness positions (e.g. physical activity coordinators, specialists, consultants) as a result of the enhanced social and political climate to promote physical activity. Recent federal reorganization shifted physical activity promotion from health promotion to chronic disease prevention, bringing "the forward-looking and upstream work in healthy living together with disease-specific work in chronic disease prevention" (N11). A provincial informant concurred that the biggest change in the last five years has been "recognition of the issue of physical inactivity and getting the government to come on side with allocating some resources and policies towards that" (PT3). In addition to government changes, organizations also noted that major sporting events, e.g. the 2010 Olympics in Vancouver and the success of Canadian athletes in the Olympics, has helped to give prominence to physical activity in public and government agendas. Some organizations saw increased enrolment and interest in their recreational and competitive programs following the Olympic Games, and others felt that these sporting events helped to build a "sphere of influence," a growing awareness and interest in physical activity.

With respect to capacity changes related to infrastructure, a recurring theme was technological improvements, particularly with web-technologies. Informants explained that increased use of electronic listservs, electronic newsletters and magazines, webinar resources, and online training/ educational sessions have facilitated faster and cost-effective communications and improved resource sharing between organizations and the public. In this way, organizations with limited budgets for promotion and communication were able to share best practices and receive feedback from distant partners.

About one-quarter of all informants reported an increase in financial resources over the last five years, primarily through grants from various ministries and partner agencies. This helped them to implement organizational strategies such as building physical activity facilities, expanding programming, hiring new/specialized staff or creating full-time from part-time positions, and expanding promotion/marketing strategies to include social media. On the flipside, a few organizations at each level explained that budgets became tighter in the last five years, and funding cuts affected staffing. Organizations that were dependent on grants were cognizant that even if they were financially secure at the moment, funding was short term and there would be a scramble to find additional resources when the end of the funding period approached.

\section{Facilitators and barriers to build capacity to promote physical activity}

When asked to think about key factors supporting or hindering capacity to mobilize and advocate for physical activity, 
principal facilitators were partnerships, alliances and collaborations, and human resources, e.g. highly skilled employees, a supportive board of directors and/or a strong volunteer and member base. Informants spoke of working alongside passionate individuals who prioritized physical activity even when their mandate had a broad focus on health or wellness. For organizations with access to sponsorships, sponsors were often perceived as vehicles to fund initiatives and help disseminate physical activity messages. In this way, sponsors simultaneously enhanced multiple aspects of organizational capacity.

The third most frequently cited facilitator for capacity was the presence of physical activity on the public and government agendas. For example, one national informant described the current Canadian climate as one that is

more holistic and a more multi-factor[ial] approach to increasing physical activity and looking at health from that perspective.... I think that the climate and that collaboration is being supported politically more so than it has been in the past and [physical activity is] being recognized as a solution. (N2)

New physical activity research and wide dissemination of research findings were seen as vital to elevating and keeping physical activity in the public and political eye. With new evidence-based and dosespecific Canadian Physical Activity Guidelines released in 2011, ${ }^{18}$ and yearly Active Healthy Kids Canada Report Cards ${ }^{19}$ disseminated primarily online since 2005 , several informants felt that they had better access to credible and relevant information than ever before. A provincial informant explained that the Report Card "brings some of the best research of the year together in one spot, so we don't have to go looking for it. It is a great advocacy tool for us" (PT1). Having evidence at their fingertips added credibility to their work and helped to gain community buy-in.

With respect to barriers for capacity, three main issues were made apparent: limited or short-term financial resources, limited or turnover of human resources, and inability to reach all communities or populations. For the most part, these three infrastructural issues were interlinked because a lack of funds constrained staffing and more staff was required to fully address the needs within their communities or expand their work to meet a wider population. As explained by a provincial informant, “While we've got passionate, excited folks doing great work at that level, bodies would be really helpful. And it is not expertise - it is actual bodies to do work" (PT1). Some organizations attempted to fill this void with volunteers, but even then, a paid staff member was required to manage and train volunteers. Regardless of their level of engagement, most organizations felt that sustainable funding would strengthen their capacity to motivate and advocate for physical activity.

\section{ParticipACTION's influence on capacity}

When asked directly to comment on ParticipACTION's influence on organizational capacity, feelings were mixed. Nearly all organizations had engaged with ParticipACTION by partnering or participating in an initiative or using resources (e.g. website, social media), yet there was reluctance to consider this engagement substantial or draw links to organizational capacity. For instance, nearly one-third had shared or used ParticipACTION's newsletters or Tweets, but few felt that this added value. Even though there was a general consensus that ParticipACTION had strengthened physical activity messaging, this was often cited as complementary to work already being done, not a novel contribution to the 'will' dimension of capacity. As expressed by one provincial informant, "I think that we get a certain amount of synergy from having a national voice as well as a provincial voice" (PT2).

In some provinces, formal partnership agreements were signed between governments and ParticipACTION. However, even in these instances, feelings were mixed. Partnerships sometimes meant that ParticipACTION's initiatives and social marketing campaigns were officially co-branded, giving organizations access to ParticipACTION's polished products and reputation. One provincial informant felt that having a formal relationship was beneficial because key decision-makers "viewed the brand as a very powerful lever in order to get messages to [the province]" (PT4). Another informant agreed that the partnership agreement was beneficial for organizational infrastructure because it "provided additional resources, especially for me to go to my networks and communities that I work with in promoting physical activity” (PT16). Conversely, some agreements meant that government funds previously set aside for initiatives and campaigns were reallocated to ParticipACTION, putting a stop to prepartnership efforts. This in turn led to frustration for departments involved in developing projects, not only because their work was pushed aside, but also because decisions to sign the agreement were made at the highest organizational levels without their consultation. It appeared that there was no consensus on the effectiveness of formal partnership agreements between ParticipACTION and provincial/territorial organizations.

Divergent perspectives on ParticipACTION's influence on capacity were also expressed depending upon whether an organization was established before or after ParticipACTION's relaunch. For instance, an informant from a new organization explained that ParticipACTION had strengthened leadership aspects of their capacity: "We met with ParticipACTION in our first year of operation and they... engaged us in their network and they've been very supportive in terms of furthering our network and our word-of-mouth [publicity]" (N2). More established organizations perceived minimal effect, given that they had been functioning well without ParticipACTION. In fact, some larger organizations felt that they had actually increased ParticipACTION's capacity by introducing ParticipACTION to key players in the Canadian physical- activity landscape or by presenting unique opportunities for disseminating messages soon after relaunch. A local informant explained,

To be honest, I think we have provided for them an opportunity to access an environment... they bring good ideas to the table, so marketing, communications and outreach, [but] in terms of their contribution to our capacity to execute, I'd say it is very small. (L1)

Finally, some informants were unsure what ParticipACTION had done in the last five years to provide any feedback.

\section{Expectations and challenges of working with ParticipACTION}

There were mixed perceptions about expectations of ParticipACTION and contributions 
over the last five years. Half of all informants had anticipated that the new ParticipACTION would serve as a national voice and brand for physical activity in Canada, thereby fostering the 'will' and 'policymaking' dimension of capacity among organizations. While most agreed that ParticipACTION had provided national messaging, some felt that ParticipACTION's campaigns focussed too closely on children and youth, neglecting the full range of Canadians, particularly with respect to age, class/income, and ability. Informants were sympathetic to the limits of funding and reach, but many still felt that ParticipACTION should play a stronger advocacy role.

With respect to leadership, several organizations agreed that ParticipACTION had influenced them by bringing key physical activity players together in virtual space through their ParticipACTION Partner Network. Organizations within this network received periodic e-blasts about upcoming campaigns and initiatives, and had access to electronic fact sheets, research and marketing materials. Given the seven-year lapse in Canada, another key expectation was that ParticipACTION would leverage the expertise of existing physical activity organizations by providing a facilitative or collaborative-style of leadership. This expectation was poorly met: "ParticipACTION needs to drive on building linkages with what already exists versus potentially creating new things because there are many things that do exist" (N10). At the same time, many organizations that participated in ParticipACTION initiatives, namely Sports Day in Canada ${ }^{20}$ appreciated the ease of taking part in a national event. Organizations shifted and rebranded preexisting programs to align with Sports Day in Canada and took advantage of the momentum surrounding this national event. A local informant explained that

having those links to greater national campaigns is really great for us because it gives us a little bit of a framework as well as the marketing materials that we are able to work with and create a greater sense of participation. (L6)

Overall, it appeared that ParticipACTION had influenced leadership aspects of capacity for Canadian physical activity organizations; however, a stronger collaborative approach was expected with national and provincial/territorial organizations.

Another point of discussion was challenges of working with ParticipACTION. Although the majority of organizations did not experience challenges, issues on competition for funding and media attention, and concerns with ParticipACTION's partnership with Coca-Cola emerged. As previously mentioned, one challenge, particularly at the provincial/territorial level was competition for funding. One provincial informant cautioned that ParticipACTION should be "careful that they don't view themselves as sort of the only leader in this area... in some cases, there may be some resentment because ParticipACTION's got the money that might have otherwise gone to some of these other groups" (PT14). A related challenge was for attention in the media and public eye. Most media outlets limit airtime and page-time devoted to physical activity messaging, and some informants noted that when ParticipACTION was granted space, their own organization was not. A desire was expressed for concurrent messaging, that is, the continuity of local or provincial/ territorial messaging while adding ParticipACTION's voice to the mix. In order to achieve this, more cooperation in "media buys" and better communication on strategic focuses and campaigns would be preferable in the future.

The most frequently cited concern, expressed by one-quarter of all informants, was ParticipACTION's partnership with the Coca-Cola Company in the Teen Challenge initiative. This particular corporate sponsorship created the greatest obstacles for organizations whose mandates spanned the areas of physical activity and healthy eating, or those with partners focussed on healthy eating. Some organizations were unable to publically engage with ParticipACTION and others only disseminated information or partnered in initiatives unrelated to Teen Challenge. A provincial partner explained,

We have partners that have some very strong concerns with the corporate sponsorship around Coca-Cola in terms of the healthy eating component.... [It has] indirectly affected us because of our partners that have put a ban and do not want to promote ParticipACTION within their networks because of that. (PT16)
At the same time, most organizations that cited Coca-Cola's sponsorship as a challenge understood that finding sponsors is not an easy task, and ParticipACTION needed financial support to continue their work.

\section{Future role and recommendations for ParticipACTION}

When thinking about ParticipACTION's future role, half of the informants recommended continued efforts in building the brand, and more communication and collaboration with stakeholders, especially around initiatives. Suggestions included creating professional development webinars on social marketing; organizing forums for physical activity stakeholders; providing sport and leadership training; linking campaigns to community action; and providing tips to leverage the ParticipACTION brand. If ParticipACTION's marketing expertise was shared, organizations could better reach their target audiences and leverage ParticipACTION's efforts, in turn helping to achieve the endgoal of increasing population physical activity levels.

Key to serving as the national voice of physical activity, several informants felt that ParticipACTION should have a greater presence in policy and advocacy. Areas frequently mentioned were advocacy to increase government funding for physical activity (or subsidies), and advocacy to address and respond to timely events that may hinder physical activity, e.g. municipal removal of bike lanes and rising socioeconomic barriers to physical activity. It was not enough to simply encourage physical activity, it was also important to alleviate barriers to physical activity, particularly among the least active populations and those experiencing the greatest challenges. One informant critiqued ParticipACTION's focus on self-promotion, saying, "every time I see ParticipACTION in the media, it is talking about a ParticipACTION initiative, not necessarily the issues that prevent people from being physically active or things that would enhance opportunities for being physically active" (L1). If a portion of ParticipACTION's communications and marketing budget could be earmarked for advocacy efforts, the goal of serving as a national voice of physical activity may be more appropriate and better achieved. 
Knowledge exchange was cited as another area to augment ParticipACTION's influence on organizational capacity. ParticipACTION's website could showcase the range of physical activities, organizations, and volunteer opportunities in communities, bringing attention to the diversity of options available for the general population and supports already in place across Canada. Through the ParticipACTION Partner Network, ParticipACTION could also build a repository of best practices in Canada and knowledge/practice gaps by population groups. If this were disseminated widely, potential solutions may arise. One provincial informant expressed this recommendation for ParticipACTION's future role as follows: “[ParticipACTION's] strength is its partnerships that are in place. It is pulling the stakeholders together across the country, and then that gives a great opportunity to analyze what's happening and share those models, or best practices" (PT18). In effect, ParticipACTION could enhance leadership and infrastructural aspects of organizational capacity by becoming a 'clearing house' for information, ideas, and professional development opportunities.

\section{Discussion}

The first objective of this study was to compare perceptions of organizational capacity at baseline and follow-up. In line with baseline findings, ${ }^{9,10}$ current capacity to promote physical activity in Canada was considered good, and had improved over the last five years; however, there were nuanced differences in the ways that capacity was discussed.

At both baseline and follow-up, informants spoke of will and policymaking as conducive to physical activity promotion in Canada. Baseline informants attributed the strength of this dimension to internal policies and strategies, and the wider societal climate resulting from the "obesity crisis". At follow-up, the wider climate appeared to reflect external social and political changes instead. Specifically, informants felt that physical inactivity has recently been recognized as an issue at federal and provincial levels, with federal efforts shifting from the area of health promotion to chronic disease prevention. This shift signals an appreciation that physical activity is not simply desirable; it is critical for a healthy population. Informants also explained that the creation of new Physical Activity Guidelines, yearly dissemination of physical activity research through the Active Healthy Kids Canada Report Cards, as well as Canada's hosting of the 2010 Olympic Games, all elevated the status of physical activity, thereby fostering an environment more receptive to its promotion and messaging than ever before.

Differences in the will dimension of capacity appear to be reflective of changes over the last five years, however, sample differences may play a part. In the followup study, there were half as many national (12), a similar number of provincial/territorial (18), and more than twice as many local organizations (14). The baseline sample was comprised primarily of higher-level organizations and focussed on aspects of will and policymaking internal to their organizations, as many had clearly defined mandates and strategic directions to reinforce this aspect of capacity. The present sample (weighted heavier with local organizations) highlighted factors external to organizations as vital contributors to the "sphere of influence," as they were more involved with, and influenced by, physical activity programming rather than broad policies. Moreover, lack of a national physical activity policy and disjointed provincial and educational policies were key subthemes in the baseline study ${ }^{9}$ but seldom mentioned at follow-up. At follow-up, the main challenge for political will was the need to increase the public "voice" of physical activity in comparison to other industry sectors, which required ongoing advocacy efforts.

Perceptions of leadership capacity were positive at baseline and follow-up, with the strength of inter-sectoral partnerships, collaborations and alliances highlighted at both time points. Collaborations, particularly with ParticipACTION, sometimes posed challenges in the form of competition for media time. Even so, partnerships helped to maximize limited human and financial resources and this aspect of capacity experienced the greatest growth over the last five years.

When it came to infrastructure, financial and human resources were of concern at baseline and follow-up, with technological advancements viewed as a mechanism to offset limitations at follow-up. Baseline informants spoke of the instability of funding from governments, grants and corporate sponsorships. Funder priorities constrained how funds could be spent and which organizational goals could be fulfilled. Limited and short-term financial resources were also barriers at follow-up, restricting the staff that could be hired and retained. At the same time, follow-up informants felt that new sources of funding and sponsorships had emerged in the last five years, paving the way for specialized staff positions in physical activity promotion. As such, in spite of funding challenges, skilled and motivated employees were explicitly identified as capacity strengths in the present study.

The second objective of this research was to examine whether ParticipACTION used or enhanced organizational capacity to promote physical activity five years after its relaunch. There were mixed perceptions about ParticipACTION's influence on capacity across all levels of organizations, with local organizations least likely to attribute capacity changes to ParticipACTION. Many informants agreed that the resurgence of ParticipACTION has brought more attention to the issue of inactivity, but this contribution was generally described as a complement to work already taking place across the nation. Beyond partnering in a one-off event run by ParticipACTION, few organizations engaged with ParticipACTION or used their resources. Some informants were simply unaware of what ParticipACTION had to offer. Although ParticipACTION has played a leading role in mass media campaigns for physical activity since relaunch, ${ }^{21,22}$ another strategic priority was knowledge exchange with physical activity organizations. ${ }^{23}$ It could be that ParticipACTION needs to make their core activities apparent to organizations by devoting more time to sharing knowledge products with the ParticipACTION Partner Network, and showcasing current activities that may enhance capacity to deliver physical activity programming.

Informants at the provincial and territorial level with formal organizational relationships to ParticipACTION also voiced mixed perceptions. Some experienced enhanced capacity from the financial and knowledge resources provided through their partnership, while others felt that the reallocation of resources from their department or region to ParticipACTION compromised pre-existing efforts. Organizations that were created since the relaunch appeared to benefit most from 
ParticipACTION, with enhancements to leadership capacity through the ParticipACTION Partner Network and a shorter "ramping up" period. Collaborative approaches that build upon the contextual knowledge and experience of provincial/ territorial organizations and also use the reach of ParticipACTION as a national organization may help to minimize these tensions and focus on the common goal of enhancing physical activity among Canadians. It could also be that greater transparency is required with respect to the amount of funding received and how ParticipACTION uses it within a particular province/territory.

Recommendations for ParticipACTION's future role centred upon increasing communication and collaboration with stakeholders, playing a greater advocacy role, providing facilitative leadership, and creating new knowledge exchange mechanisms. It was widely believed that ParticipACTION is armed with social marketing expertise, and informants wished for more opportunities to glean and apply this knowledge in their work. Several organizations also expected more from a "national voice" in terms of the breadth of their messaging (e.g. population targets) and involvement in advocacy. Given ParticipACTION's mandate to serve all Canadians, it may be important to describe how they will reach various population groups within their strategic plans, what role they will play in physical activity advocacy, or how they will support existing efforts in physical activity promotion, delivery and advocacy.

\section{Conclusion}

This study fills a literature gap on how a social marketing organization can influence organizational capacity to promote physical activity over time and at a national level. According to participants, organizational capacity to promote physical activity in Canada has increased over five years since ParticipACTION's relaunch in subtle but important ways. Although it might have been that informants with positive perspectives of capacity were more likely to participate in the study, similar perspectives from individuals representing a range of organizational sectors and mandates, as well as representation from all provinces and territories, lends support to our findings. As well, we used a theoretical framework that accommodates diverse perspectives, and an analysis strategy that sought to demonstrate interrelationships between the themes in order to present the complexity of issues faced by physical activity organizations. Leadership and the general climate for physical activity promotion have improved, while infrastructure (particularly financial resources) continues to constrain the ability of organizations to fulfil their mandates. ParticipACTION has had an influence on capacity among newer and smaller organizations; however, their influence across all levels and types of organizations appears to be limited. Overall, minimal attribution of capacity changes to ParticipACTION may be due to a lack of awareness of ParticipACTION's activities, competing interests among organizations, or it could simply be that more time is required before direct influence on capacity is experienced and acknowledged by organizations. A final consideration is that the influence of any one particular organization might be limited given that system-level social and environmental change is necessary to increase physical activity at a population level. ${ }^{24}$

\section{Acknowledgements}

We would like to thank all informants for candidly sharing their perspectives with us. This project was made possible by an operating grant from the Canadian Institutes of Health Research (MOP123491). Guy Faulkner holds a Canadian Institutes of Health Research-Public Health Agency of Canada (CIHR-PHAC) Chair in Applied Public Health. Amy Latimer-Cheung and Tanya R. Berry receive support from the Canada Research Chairs Program.

\section{Conflicts of interest}

GF, TB, SD, AEL, RER, MST and JS serve on the ParticipACTION Research Advisory Group.

\section{Authors' contributions and statement}

GF conceptualized the design of the study. SR led data collection and analysis, and wrote the first draft. GF, TB, SD, AELC, RER, MST, and JCS provided input to study design, analysis, and interpretation, and in drafting and revising the paper. All authors have seen and approved the final manuscript.

The content and views expressed in this article are those of the authors and do not necessarily reflect those of the Government of Canada.

\section{References}

1. Tremblay MS, Shields M, Laviolette M, Craig CL, Janssen I, Gorber SC. Fitness of Canadian children and youth: results from the 2007-2009 Canadian Health Measures Survey. Health Rep. 2010;21(1):7-20.

2. Shields M, Tremblay MS, Laviolette M, Craig CL, Janssen I, Gorber SC. Fitness of Canadian adults: results from the 2007-2009 Canadian Health Measures Survey. Health Rep. 2010; 21(1).

3. Colley RC, Garriguet D, Janssen I, Craig CL, Clarke J, Tremblay MS. Physical activity of Canadian children and youth: accelerometer results from the 2007 to 2009 Canadian Health Measures Survey. Health Rep. 2011; 22(1):1-9.

4. Colley RC, Garriguet D, Janssen I, Craig CL, Clarke J, Tremblay MS. Physical activity of Canadian adults: accelerometer results from the 2007 to 2009 Canadian Health Measures Survey. Health Rep. 2011;22(1):1-8.

5. Rootman I, Edwards P. The best laid schemes of mice and men ... ParticipACTION's legacy and future of physical activity promotion in Canada. Can J Public Health. 2004; 95:S37-S42.

6. Tremblay MS, Craig CL. ParticipACTION: Overview and introduction of baseline research on the "new" ParticipACTION. Int $\mathrm{J}$ Behav Nutr Phys Act. 2009;6. doi: 10.1186/1479 $-5868-6-84$.

7. Ramanathan S, Allison KR, Faulkner G, Dwyer JJM. Challenges in assessing the implementation and effectiveness of physical activity and nutrition policy interventions as natural experiments. Health Promotion International. 2008;23(3):290-7. doi: 10.1093/heapro/dan022.

8. Spence JC, Brawley LR, Craig CL, et al. ParticipACTION: Awareness of the participACTION campaign among Canadian adults - Examining the knowledge gap hypothesis and a hierarchy-of-effects model. Int $\mathrm{J}$ Behav Nutr Phy. 2009;6. doi: 10.1186/1479 $-5868-6-85$. 
9. Faulkner G, McCloy C, Plotnikoff RC, et al. ParticipACTION: Baseline assessment of the capacity available to the 'New ParticipACTION': A qualitative study of Canadian organizations. Int J Behav Nutr Phy. 2009;6. doi: 10.1186/1479-5868-6-87.

10. Faulkner G, McCloy C, Plotnikoff RC, Tremblay MS. Relaunching a national social marketing campaign: expectations and challenges for the "new" ParticipACTION. Health Promot Pract. 2011;12(4):569-76.

11. Smith C, Raine K, Anderson D, Dyck R, Plotnikoff R, Ness K, et al. A preliminary examination of organizational capacity for heart health promotion in Alberta's regional health authorities. Promot Educ. 2001;Suppl 1:40-3.

12. Dressendorfer RH, Raine K, Dyck RJ, et al. A conceptual model of community capacity development for health promotion in the Alberta Heart Health Project. Health Promot Pract. 2005; 6(1):31-6. doi: 10.1177/1524839903 259302.

13. Faulkner G, Ramanathan S, Plotnikoff RC, et al. ParticipACTION after 5 years of relaunch: a quantitative survey of Canadian organizational awareness and capacity regarding physical activity initiatives. Health Promot Chronic Dis Prev Can. 2018;38(4): 162-9.

14. Robinson K, Elliott SJ, Driedger SM, et al. Using linking systems to build capacity and enhance dissemination in heart health promotion: a Canadian multiple-case study. Health Educ Res. 2005;20(5):499-513. doi: 10.1093/her /cyh006.

15. Poland BD. Transcription quality. In: Gubrim JF, Holstein JA, editors. Handbook of Interview Research: Context \& Method. California: Thousand Oaks; 2002. p. 629-49.

16. Braun V, Clarke V. What can "thematic analysis" offer health and wellbeing researchers? International journal of qualitative studies on health and well-being. 2014;9:26152. doi: 10.3402/qhw.v9.26152.

17. Braun V, Clarke V. Using thematic analysis in psychology. Qualitative Research in Psychology. 2006;3(2): 77-101.
18. Tremblay MS, Warburton DER, Janssen I, et al. New Canadian Physical Activity Guidelines for Canadians. Appl Physiol Nutr Metab. 2011;36(1):36-46. doi: 10.1139/H11 -009 .

19. Active Healthy Kids Canada. Is active play extinct? Toronto: Active Healthy Kids Canada, 2012. Available from: http://www.vivo.ca/uploads/PDFs /Active_Healthy_Kids_Report_Card.pdf

20. White L, Luciani A, Berry TR, et al. Sports day in Canada: a longitudinal evaluation. Int $\mathrm{J}$ Health Promot and Educ. 2016;54(1):12-23. doi: 10.1080 $/ 14635240.2015 .1050122$.

21. Craig CL, Bauman A, Latimer-Cheung A, et al. An evaluation of the my ParticipACTION campaign to increase self-efficacy for being more physically active. J Health Commun. 2015;20(9): 995-1003. doi: 10.1080/10810730.2015 .1012240 .

22. Gainforth HL, Jarvis JW, Berry TR, et al. Evaluating the ParticipACTION "Think Again" Campaign. Health Educ Behav. 2016;43(4):434-41.

23. Faulkner G, Yun L, Tremblay MS, Spence JC. Exploring the impact of the 'new' ParticipACTION: overview and introduction of the special issue. Health Promot Chronic Dis Prev Can. 2018;38(4):153-61.

24. Sallis JF, Owen N. Ecological models. In: Glanz K, Lewis F, Rimer B, editors. Health Behavior and Health Education. San Francisco: JosseyBass; 1997. p. 403-24. 